\title{
Presence of harmless small supernumerary marker chromosomes hampers molecular genetic diagnosis: a case report
}

\author{
HEIKE NELLE $^{1,2}$, ISOLDE SCHREYER ${ }^{1,3}$, ELISABETH EWERS ${ }^{1}$, KRISTIN MRASEK $^{1}$, \\ NADEZDA KOSYAKOVA ${ }^{1}$, MARTINA MERKAS ${ }^{1,6}$, AHMED BASHEER HAMID ${ }^{1}$, RAIMUND FAHSOLD ${ }^{4}$, \\ ANIKÓ UJFALUSI ${ }^{7}$, JASEN ANDERSON ${ }^{8}$, NIKOLAI RUBTSOV ${ }^{9}$, ALMA KÜCHLER ${ }^{5}$, \\ FERDINAND VON EGGELING ${ }^{1}$, JULIA HENTSCHEL ${ }^{1}$, ANJA WEISE $^{1}$ and THOMAS LIEHR ${ }^{1}$ \\ ${ }^{1}$ Institute of Human Genetics and Anthropology; ${ }^{2}$ Clinic for Children and Juvenile Medicine, \\ Jena University Hospital, 07740 Jena; ${ }^{3}$ Center for Ambulant Medicine - Jena University Hospital gGmbH, \\ Practice for Human Genetics, 07743 Jena; ${ }^{4}$ Middle German Practice Group, 01067 Dresden; ${ }^{5}$ Institute of Human Genetics, \\ 45122 Essen, Germany; ${ }^{6}$ School of Medicine Zagreb University, Croatian Institute for Brain Research, 1000 Zagreb, \\ Croatia; ${ }^{7}$ University of Medical and Health Science Center, Department of Pediatrics, Genetic Laboratory, \\ Debrecen 4032, Hungary; ${ }^{8}$ Department of Cytogenetics, Sullivan Nicolaides Pathology, Taringa QLD, \\ Australia; ${ }^{9}$ SA of RAderW, Institute of Cytologie and Genetics, 630090 Novosibrisk, Russian Federation
}

Received April 7, 2010; Accepted May 25, 2010

DOI: $10.3892 / \mathrm{mmr} 00000299$

\begin{abstract}
Mental retardation is correlated in approximately $0.4 \%$ of cases with the presence of a small supernumerary marker chromosome (sSMC). However, here we report a case of a carrier of a heterochromatic harmless sSMC with fragile X syndrome (Fra X). In approximately $2 \%$ of sSMC cases, similar heterochromatic sSMC were observed in a clinically abnormal carriers. In a subset of such cases, uniparental disomy (UPD) of the corresponding sister chromosomes was shown to be the cause of mental retardation. For the remainder of the cases, including the present one, the sSMC was just a random finding not related to the clinical phenotype. Thus, it is proposed to test patients with heterochromatic sSMC and mental retardation of unclear cause as follows: i) exclude UPD, ii) test for Fra $\mathrm{X}$ as it is a major cause of inherited mental retardation, and iii) perform chip-based assays or tests for special genetic diseases according to the phenotype. In any case, the diagnosis of a cytogenetic aberration such as an sSMC should not automatically be considered the resolution of a clinical case.
\end{abstract}

\section{Introduction}

Small supernumerary marker chromosomes (sSMC) are a morphologically heterogeneous group of structurally abnormal chromosomes, including various types of inverted duplicated

Correspondence to: Dr Thomas Liehr, Institut für Humangenetik und Anthropologie, Postfach, D-07740 Jena, Germany

E-mail: i8lith@mti.uni-jena.de

Key words: small supernumerary marker chromosome, fragile $\mathrm{X}$-syndrome, unclear mental retardation chromosomes, minute chromosomes and ring chromosomes. sSMC can only be characterized unambiguously by molecular (cyto)genetics and are equal in size or smaller than a chromosome 20 of the same metaphase spread (1). The phenotypes associated with the presence of an sSMC vary from normal to severely abnormal (2). It is particularly difficult to determine clinical outcome in pre-natally ascertained cases with small markers that are de novo. For such cases with sSMC, the risk of an abnormal phenotype is $26-30 \%$ (2). Recently, progress for genotype-phenotype correlation in SSMC was achieved by summarizing the available sSMC cases in a database $(2,3)$. Thus, the presence of centromere-near euchromatin on an sSMC may, but must not, be correlated with an adverse prognosis. However, if there is no euchromatin on the sSMC and no uniparental disomy (UPD) in the sister chromosomes of the sSMC can be detected, in general the sSMC is regarded as harmless (2). Nonetheless, 63 cases with heterochromatic sSMC were reported by Liehr (3), in which the cause of clinical abnormalities in the corresponding patient was not clear (Tables I and II). In approximately $40 \%$ of these patients, UPD was tested (Tables I and II) and led to a diagnosis of an imprinting disorder or the activation of a recessive gene. This was the case in 18 of these cases overall (Table I). However, after the exclusion of UPD, the cause of clinical problems such as mental retardation remained unclear in $72 \%$ of heterochromatic sSMC cases (Table II).

Fragile $\mathrm{X}$ syndrome (Fra $\mathrm{X}$ ) is a major cause of inherited mental retardation affecting 1 in 2,500 individuals. For Fra $X$, cognitive dysfunction and/or impairment and various physical abnormalities, including a characteristic long, narrow face, large ears, close interoccular distance, flat feet and occasionally hyperextensible joints, are typical. In addition, speech and language skills are severely affected in males with Fra X, who often exhibit autistic-like behavior. At the cytogenetic level, chromosome spreads derived from Fra X patients grown 
Table I. Heterochromatic sSMC cases reported in the literature as having a uniparental disomy.

\begin{tabular}{|c|c|c|}
\hline Case no. in Ref. 3 & Karyotype & Uniparental disomy \\
\hline $12-\mathrm{O}-\mathrm{p} 11 / 1-1$ & $\operatorname{mos} 47, \mathrm{XX},+\min (12)(: \mathrm{p} 11 \rightarrow \mathrm{q} 11:) / 46, \mathrm{XX}$ & mat 12 \\
\hline $14-W-q 11.1 / 3-1$ & $\operatorname{mos} 47, X Y,+\min (14)(p t e r \rightarrow q 11.1:) / 46, X Y$ & mat 14 \\
\hline 14-W-q11.1/2-1 & $\operatorname{mos} 47, \mathrm{XX},+\operatorname{inv} \operatorname{dup}(14)(\mathrm{q} 11) / 46, \mathrm{XX}$ & pat 14 \\
\hline $15-\mathrm{P}-\mathrm{q} 11 / 1-2$ & $\operatorname{mos} 47, X Y,+\operatorname{inv} \operatorname{dup}(15)(q 11) / 46, X Y$ & mat 15 \\
\hline $15-\mathrm{P}-\mathrm{q} 11 / 1-4$ & $47, X X,+\operatorname{inv} \operatorname{dup}(15)(q 11)$ & mat 15 \\
\hline $15-\mathrm{P}-\mathrm{q} 11 / 1-5$ & $\operatorname{mos} 47, \mathrm{XY},+\operatorname{inv} \operatorname{dup}(15)(\mathrm{q} 11) / 46, \mathrm{XY}$ & mat 15 \\
\hline $15-\mathrm{P}-\mathrm{q} 11 / 1-13$ & $47, X Y,+\operatorname{inv} \operatorname{dup}(15)(q 11)$ & mat 15 \\
\hline 15-P-q11.1/1-1 & $\operatorname{mos} 47, X Y,+\min (15)($ pter $\rightarrow q 11.1:) / 46, X Y$ & mat 15 \\
\hline $15-\mathrm{P}-\mathrm{q} 11.1 / 2-2$ & $\operatorname{mos} 47, \mathrm{XX},+\operatorname{inv} \operatorname{dup}(15)(\mathrm{q} 11.1) / 46, \mathrm{XX}$ & mat 15 \\
\hline 15-P-q11.1/2-4 & $\operatorname{mos} 47,+\operatorname{inv} \operatorname{dup}(15)(q 11.1) / 46$ & mat 15 \\
\hline $15-P-q 11.1 / 2-5$ & $\operatorname{mos} 47,+\operatorname{inv} \operatorname{dup}(15)(q 11.1) / 46$ & mat 15 \\
\hline $15-P-q 11.1 / 2-6$ & $\operatorname{mos} 47, \mathrm{XY},+\operatorname{inv} \operatorname{dup}(15)(q 11.1) / 46, X Y$ & mat 15 \\
\hline $22-U-40$ & $\operatorname{mos} 47, X Y,+\operatorname{inv} \operatorname{dup}(22)(q 11.1) / 46, X Y$ & mat 15 \\
\hline $15-\mathrm{A}-\mathrm{q} 11 / 1-1$ & $\operatorname{mos} 47, X Y,+\operatorname{inv} \operatorname{dup}(15)(q 11) / 46, X Y$ & pat 15 \\
\hline $15-\mathrm{A}-\mathrm{q} 11 / 1-2$ & 47,XY,+inv dup(15)(q11) & pat 15 \\
\hline 16-W-p11.1/3-1 & $\operatorname{mos} 47, \mathrm{XY},+\mathrm{r}(16)(:: \mathrm{p} 11.1 \rightarrow \mathrm{q} 11.2::) / 46, \mathrm{XY}$ & mat 16 \\
\hline 20-W-p11.1/2-1 & $47, X Y,+\min (20)(: p 11.1 \rightarrow q 11.1:)$ & mat 20 \\
\hline $22-\mathrm{O}-\mathrm{q} 11 / 2-1$ & $\operatorname{mos} 47, X X,+\min (22)(: p 11.1 \rightarrow q 11:) / 46, X X$ & mat 22 \\
\hline
\end{tabular}

Mat, maternal; Pat, paternal.

under specific cell culture conditions show a gap or break on the X-chromosome in the fragile site FRAXA at Xq27.3. On the molecular level, the fragile site is caused by a CGG triplet expansion (dynamic mutation) to more than 200 repeats located within the 5 ' untranslated region of the Fragile $\mathrm{X}$ Mental Retardation 1 (FMR1) gene. Due to X-inactivation, females with the full mutation normally show a milder or no phenotype. Normal individuals carry 6-54 CGG repeats, while alleles with 55-200 triplets are considered 'pre-mutated' genes. The pre-mutation is unstable and commonly expands during intergenerational transmission. Notably, the repeat is more stable during male transmission, and the full mutation is inherited only from the mother (4).

Here, we report the case of a 2-year-old boy with mental retardation, in which the diagnosis of a Fra X was slightly delayed by the knowledge that he was carrier of a heterochromatic sSMC; we also summarize possibly comparable cases from the literature.

\section{Materials and methods}

Case report. We treated a 2.25-year-old male patient (P1), who was the first child of healthy and non-consanguineous parents (Fig. 1). The patient showed a combined developmental delay (particularly in speech) of a to date unknown genesis. The pregnancy and birth proceeded well. The boy had an increased head circumference ( $>97$ th percentile), weight between the 90th and 95th percentiles and height in the 75 th percentile. The facial appearance showed a prominent forehead, a long face with a pointed chin, red cheeks, a thin upper lip, sparse hair growth with a receding hairline and pasty skin. The aunt of the patient (the sister of the mother)

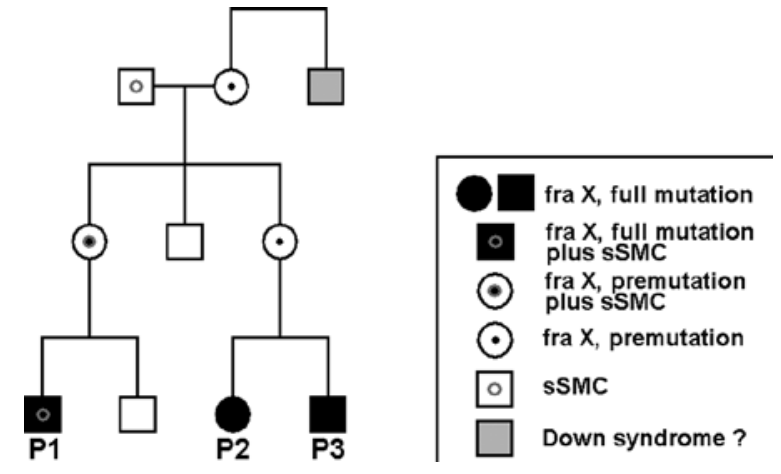

Figure 1. Pedigree of the index patient P1 and his family.

had two children (boy, P2; girl, P3), both with developmental delay of unclear genesis. It was suggested that an uncle of the mother (the brother of her mother) had Down syndrome, but this had never been tested cytogenetically (Fig. 1). At the time of the initial consultation, the mother of P1 was pregnant and in the 10 th week of gestation.

Cytogenetics and molecular cytogenetics. For karyotypic investigations, metaphase chromosomes were obtained according to standard procedures using PHA stimulated 72-h cultures of peripheral blood lymphocytes from P1, his parents and his maternal grandparents. The analysis of GTG-banded chromosomes was carried out according to standard procedures. To clarify the origin and genetic content of the detected sSMC, centromere-specific multicolor fluorescence in situ hybridization (FISH) was carried out as previously reported in the acrocentric chromosome directed (acrocenM-FISH) version 
Table II. Heterochromatic sSMC cases with clinical symptoms reported in the literature as having no uniparental disomy (UPD) or not having been tested for UPD.

\begin{tabular}{|c|c|c|c|}
\hline Case no. in Ref. 3 & Age at diagnosis (years) & Karyotype & UPD tested \\
\hline 01-W-p11.1/1-1 & 8 & $\operatorname{mos} 47, \mathrm{XX},+\min (1)(: \mathrm{p} 11.1 \rightarrow \mathrm{q} 12:)$ & - \\
\hline 01-W-p11.1/1-2 & 2 & $\operatorname{mos} 47, \mathrm{XX},+\min (1)(: \mathrm{p} 11.1 \rightarrow \mathrm{q} 12:)$ & - \\
\hline $01-\mathrm{W}-\mathrm{p} 11 / 2-1$ & pre-natal & $\operatorname{mos} 47, X Y,+r(1)(:: p 11 \rightarrow q 11::) / 46, X Y$ & - \\
\hline $01-\mathrm{W}-\mathrm{p} 11 / 3-1$ & 2 & $\operatorname{mos} 47, \mathrm{XX},+\min (1)(: \mathrm{p} 11 \rightarrow \mathrm{q} 11:) / 46, \mathrm{XX}$ & - \\
\hline 02-W-p11.1/3-1 & 41 & $47, X Y,+\min (2)(: p 11.1 \rightarrow q 11.1:)$ & + \\
\hline 03-W-p10/1-1 & 1 & $\operatorname{mos} 47, \mathrm{XX},+\mathrm{r}(3)(:: \mathrm{p} 10 \rightarrow \mathrm{q} 11::) / 46, \mathrm{XX}$ & - \\
\hline 04-W-p11/1-1 & 1 & $\operatorname{mos} 47, \mathrm{XX},+\min (4)(: \mathrm{p} 11 \rightarrow \mathrm{q} 11:) / 46, \mathrm{XX}$ & - \\
\hline $04-\mathrm{W}-\mathrm{p} 11 / 1-2$ & 3 & $\operatorname{mos} 47, \mathrm{XY},+\min (4)(: \mathrm{p} 11 \rightarrow \mathrm{q} 11:) / 46, \mathrm{XY}$ & + \\
\hline 05/19-W-1 & child & $\begin{array}{l}\operatorname{mos} 47, X Y,+\min (1)(: p 11 \rightarrow q 11:) \text { or } \\
\min (5)(: p 11 \rightarrow q 11.1:) \text { or } \min (19)(: p 11 \rightarrow q 11)\end{array}$ & - \\
\hline 07-W-p11.1/1-1 & 3 & $\operatorname{mos} 47, \mathrm{XX},+\min (7)(: \mathrm{p} 11.1 \rightarrow \mathrm{q} 11.1:) / 46, \mathrm{XX}$ & + \\
\hline 08-W-p11/1-1 & 3 & $\operatorname{mos} 47, \mathrm{XY},+\mathrm{r}(8)(:: \mathrm{p} 11 \rightarrow \mathrm{q} 11::) / 46, \mathrm{XY}$ & + \\
\hline $08-\mathrm{W}-\mathrm{p} 11 / 1-2$ & 29 & $\operatorname{mos} 47, \mathrm{XY},+\mathrm{r}(8)(:: \mathrm{p} 11 \rightarrow \mathrm{q} 11::) / 46, \mathrm{XY}$ & - \\
\hline 09-W-p11.1/1-1 & 9 & $\operatorname{mos} 47, X X,+\min (9)(: p 11.1 \rightarrow q 12:) / 46, X X$ & - \\
\hline 12-W-p11.1/3-1 & 10 & $\operatorname{mos} 47, \mathrm{XX},+\min (12)(: \mathrm{p} 11.1 \rightarrow \mathrm{q} 11:) / 46, \mathrm{XX}$ & - \\
\hline 13/21-W-q10/1-1 & post-natal & $47,+$ inv dup(13or21)(q10) & - \\
\hline 13/21-W-q10/1-2 & post-natal & $47,+$ inv dup(13or21)(q10) & - \\
\hline $13 / 21-W-q 10 / 1-3$ & 15 & 47,XY,+inv dup(13or21)(q10) & - \\
\hline 13/21-W-q11/1-1 & 0.75 & 47,XY,+inv dup(13or21)(q10) & - \\
\hline 13/21-W-q11/1-2 & pre-natal & $\operatorname{mos} 47, \mathrm{XY},+$ inv dup(13or21)(q10)/46,XY & - \\
\hline $14-W-q 10 / 1-1$ & pre-natal & 47,XY,+inv dup(14)(q10) & - \\
\hline $14-W-q 10 / 1-2$ & pre-natal & 47,XY,+inv dup(14)(q10) & - \\
\hline $15-\mathrm{W}-\mathrm{q} 11.1 / 1-1$ & 6.5 & $\operatorname{mos} 47, \mathrm{XX},+\mathrm{r}(15)(:: \mathrm{p} 11.1 \rightarrow \mathrm{q} 11.1::) / 46, \mathrm{XX}$ & - \\
\hline $15-\mathrm{W}-\mathrm{q} 11.1 / 2-1$ & post-natal & $\begin{array}{l}\operatorname{mos} 47, X X,+ \text { inv } \\
\operatorname{dup}(15)(\text { pter } \rightarrow q 11.1:: q 11.1 \rightarrow p 11.1::) / 46, X X\end{array}$ & - \\
\hline $15-W-q 11.1 / 3-1$ & newborn & 47,XY,+inv dup(15)(q11.1) & + \\
\hline $15-W-q 11.1 / 3-2$ & 11 & 47,XY,+inv dup(15)(q11.1) & - \\
\hline $15-W-q 11.1 / 3-3$ & 9 & 47,XX,+inv dup(15)(q11.1) & - \\
\hline 16-W-p11.1/1-1 & 2 & $\begin{array}{l}\operatorname{mos} 47, X Y,+\min (16)(: p 11.1 \rightarrow q 11.1 \text { or } \\
q 11.1 \rightarrow \mathrm{p} 11.1:: \mathrm{p} 11.1 \rightarrow \mathrm{q} 11.2:) / 46, X Y\end{array}$ & - \\
\hline $16-\mathrm{W}-\mathrm{p} 11.1 / 1-2$ & 13 & $\operatorname{mos} 47, X Y,+r(16)(:: p 11.1 \rightarrow q 12::) / 46, X Y$ & - \\
\hline 20-W-p11.1/3-1 & 4 & $47, X X,+\min (20)(: p 11.1 \rightarrow q 11.1:)$ & + \\
\hline $22-O-q 11.1 / 1-25^{a}$ & 2.25 & 47,XY,+inv dup(22)(q11.1)mat & + \\
\hline $22-W-q 11 / 1-1$ & n.a. & $47,+\operatorname{inv} \operatorname{dup}(22)(q 11)$ & - \\
\hline $22-W-q 11 / 1-2$ & newborn & 47,XX,+inv dup(22)(q11) & - \\
\hline $22-W-q 11 / 1-3$ & pre-natal & $\operatorname{mos} 47, \mathrm{XY},+\operatorname{inv} \operatorname{dup}(22)(\mathrm{q} 11) / 46, \mathrm{XY}$ & + \\
\hline $22-W-q 11 / 1-4$ & 11 & $48, X X,+\operatorname{inv} \operatorname{dup}(22)(q 11) \times 2$ & - \\
\hline 22-W-q11.1/1-1 & n.a. & 47,XY,+inv dup(22)(q11.1) & - \\
\hline
\end{tabular}

apresent case.

(5) and towards the centromere-near region of chromosome 22 (subcenM-FISH) (2).

Molecular genetics. A microsatellite analysis to exclude UPD of chromosome 22 was carried out as previously reported (6) using the following microsatellite markers: D22S446*, D22S1167, D22S689, D22S685*, D22S683, D22S1158*, D22S1147, D22S422, D22S445 and D22S1142. Those marked with asterisks were informative normal in $\mathrm{P} 1$.
Fra X diagnostics was carried out according to standard procedures at the Middle German Practice Group (Dresden, Germany). The individuals tested were $\mathrm{P} 1$, his parents and maternal grandparents, as well as P2, P3 and their mother.

\section{Results}

Cytogenetics and molecular cytogenetics revealed the presence of an sSMC derived from chromosome 22 in P1, his 
mother and his maternal grandfather (Fig. 1). The sSMC was characterized as inv $\operatorname{dup}(22)(\mathrm{q} 11.1)$, and thus was considered to be exclusively heterochromatic. Subsequently, the presence of an iso-UPD of normal chromosome 22 in the index patient was excluded in P1.

A re-evaluation of the pedigree and the clinical characteristics of P1 prompted a molecular analysis of the FMR1-gene, typically altered in Fra $X$. This identified a characteristic expansion of the CGG-region (430-630 repeats), which is a so-called 'full mutation' for Fra X. The subsequent molecular genetic analysis of the mother of P1 showed 83 CGG repeats in the FMR1-gene, corresponding to a pre-mutation and carrier-status for Fra X. Further analysis also identified a premutation in the grandmother of P1 and in the mother of P2 and P3. The latter had full mutations of Fra X syndrome. The current pregnancy of the mother of P1 was also studied in the 14th week of gestation, and revealed a normal male karyotype without mutation or pre-mutation in the FMR1-gene (Fig. 1).

\section{Discussion}

Even though the exclusion of Fra X should be one of the first steps in cases of mental retardation of unclear cause, the presence of sSMC in P1 first led us to investigate in the wrong direction. However, in the present case, the comprehensive clarification of the inheritance of sSMC and Fra X within the pedigree (Fig. 1) led to a risk assessment for the current pregnancy of the parents of P1. This was found to not be above the common risk, thus the pregnancy was continued and a healthy boy was born at term.

A search of the literature for heterochromatic sSMC case reports similar to the one of patient $\mathrm{P} 1$ revealed 63 such cases (Tables I and II). To date, 3,307 sSMC cases (excluding those detected in patients with Turner syndrome) have been reported. Thus, approximately $2 \%$ of cases having a heterochromatic and harmless SSMC are nonetheless observed to be clinically abnormal. In a subset of such cases, UPD of the corresponding sister chromosomes may be found. For the remainder of the cases, including ours, the sSMC is just a random finding not related to the clinical phenotype. Thus, testing patients with heterochromatic sSMC and mental retardation of unclear cause should be carried out as follows: first, UPD is to be excluded, second, Fra X should be tested, then lastly array-CGH or tests for special genetic diseases according to the phenotype should be performed. In any case, the diagnosis of a cytogenetic aberration such as an sSMC should not automatically be considered the resolution of a clinical case.

\section{Acknowledgements}

This study was supported in part by DAAD (D07/00070), BMBF/DLR (BLR 08/004 and ARM 08/001), Prochance 2008 and 2009 and DFG (LI 820/22-1).

\section{References}

1. Liehr T, Claussen U and Starke H: Small supernumerary marker chromosomes (sSMC) in humans. Cytogenet Genome Res 107: 55-67, 2004.

2. Liehr T, Mrasek K, Weise A, Dufke A, Rodríguez L, Martínez Guardia N, Sanchís A, Vermeesch JR, Ramel C, Polityko A, Haas OA, Anderson J, Claussen U, von Eggeling F and Starke H: Small supernumerary marker chromosomes progress towards a genotype-phenotype correlation. Cytogenet Genome Res 112: 23-34, 2006.

3. Liehr T: Small supernumerary marker chromosomes (sSMC). Institute of Human Genetics and Anthropology, University of Jena: http://www.med.uni-jena.de/fish/sSMC/00START.htm. Accessed Oct 23, 2010.

4. D'Hulst C and Kooy RF: Fragile X syndrome: from molecular genetics to therapy. J Med Genet 46: 577-584, 2009.

5. Trifonov V, Seidel J, Starke H, Martina P, Beensen V, Ziegler M, Hartmann I, Heller A, Nietzel A, Claussen U and Liehr T: Enlarged chromosome 13 p-arm hiding a cryptic partial trisomy 6p22.2-pter. Prenat Diagn 23: 427-430, 2003.

6. Bartels I, Schlueter G, Liehr T, von Eggeling F, Starke H, Glaubitz R and Burfeind P: Supernumerary small marker chromosome (SMC) and uniparental disomy 22 in a child with confined placental mosaicism of trisomy 22: trisomy rescue due to marker chromosome formation. Cytogenet Genome Res 101: 103-105, 2003. 